\title{
Improving the efficiency of the roller screen with circular disks
}

\author{
Alexander Kondratiev ${ }^{1, *}$, Sergei Smorodov ${ }^{1}$, Vitaliy Antsev², and Andrei Kirichek ${ }^{3}$ \\ ${ }^{1}$ Tver State Technical University, Construction, Road Machinery and Equipment Department, 170026 \\ Tver, emb. Afanasy Nikitin, 22, Russia \\ ${ }^{2}$ Tula State University, Hoisting and Conveying Machines and Equipment Department, 300012 Tula, \\ Lenin Avenue, 92, Russia \\ ${ }^{3}$ Bryansk State Technical University, University administration, 241035 Central Federal District, \\ Bryansk Region, Bryansk, 50 Years of October Boulevard, 7, Russia
}

\begin{abstract}
The design, operation and technical characteristics of the roller screen test bench with movable aprons are described. The results of studies of gravel screening on a roller device with circular disks are presented. The rational parameters of the roller screen plate are obtained: the speed of the rollers with disks, working surface canting angle, the speed of the aprons. Comparative evaluation of the efficiency and productivity of the screening process at the devices with circular and multisided disks is given.
\end{abstract}

The classification of gravel and crushed stone on screening and crushing plants of roadbuilding machines is mainly carried out on vibrating screens. At the same time, the mining industry has long used roller screens, the performance of which in some cases is 2-3 times higher than vibrating ones with relatively high quality fractionation of materials $[1,2]$. Therefore, in the designs of crushing and screening complexes of foreign firms for separating stone materials roller screens are increasingly installed [3, 4, 5].

However, practical application of roller screens allowed to reveal their main drawback which is hanging up of solid inclusions between the working elements, in particular between the multisided disk and the adjacent roller due to recurrent changes in the interval between them when rotating the rollers. To prevent hanging up of stones it was offered on the screening rollers to install circular disks instead of multisided ones and to compensate their low carrying capacity to place movable aprons over the deck plate [6].

In order to justify the parameters of the roller screen with circular disks, there was made a test bench, which scheme is shown in the figure.

The test bench consists of a frame 1 , on which consecutively placed a loading tray 2 , five rollers 3 with circular disks 4 , mounted on the rollers 3 checkerwise overlapping. Over the disks 4 along the entire length of the deck plate movable aprons 5 (active intensifiers) are installed, fixed with a certain step on the endless drive chains. Under the screen working surface there are hoppers 6 , which have containers 7 underneath for screen underflow. The disks 4 of the last roller 3 have an unloading tray 8 under which there is a surge box 9 for

\footnotetext{
*Corresponding author: anzev@,yandex.ru
} 
the material discharged from the deck plate. Before the loading tray 2, a conveyor belt 10 is installed to feed stones for screening.

The test bench works as follows. Basic material from the conveyor belt 10 along the tray 2 enters the rotating rollers 3 with disks 4, which convey the stones in the direction of the unloading tray 8 . Simultaneously with the rotating disks 4 , the movable aprons 5 , at $v$ speed along the screen also convey the stones mixture along the deck plate working surface. When moving on the deck plate the stones are divided into separate portions by the aprons 5 according to the step of their arrangement. The impact of the disks 4, and the aprons 5 on separated material ensures reliable movement of the stones along the deck plate with simultaneous intensification of screening small particles.

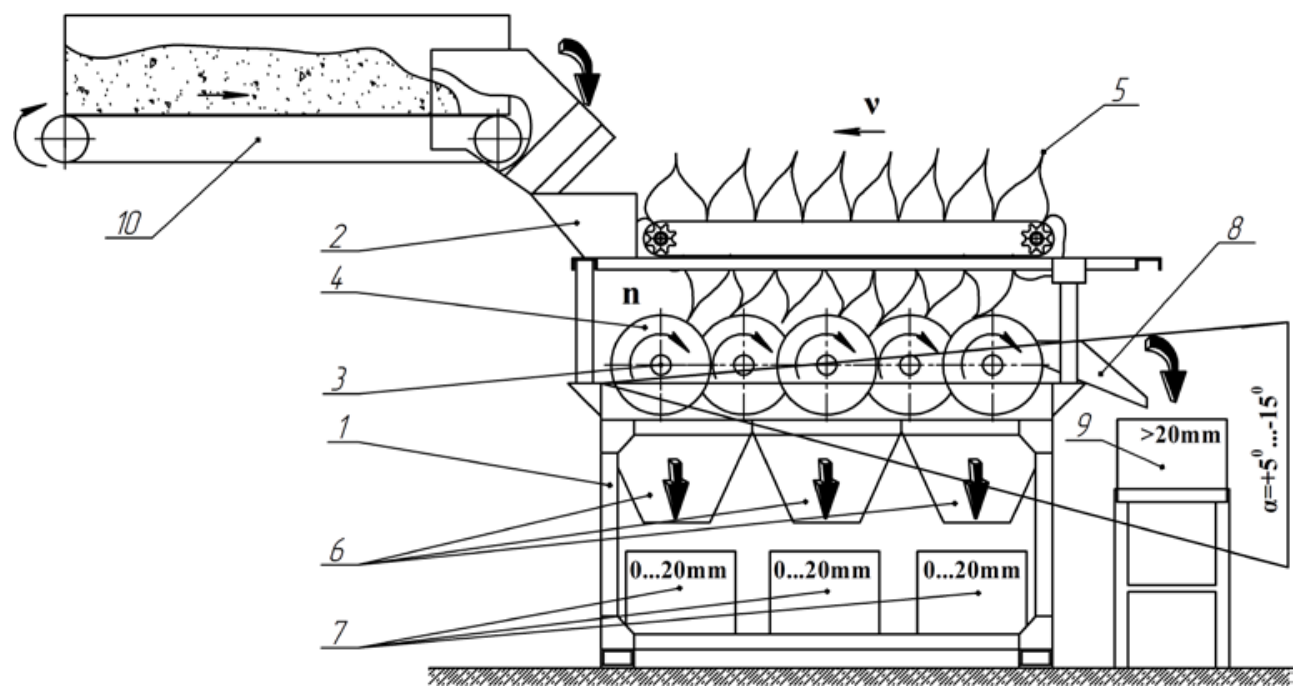

Fig. 1. Test bench scheme.

The technical characteristics of the test bench equipment were the following:

- screen parameters: working surface length is $1.35 \mathrm{~m}$, the width is $0.2 \mathrm{~m}$; number of rollers is 5; the disk shape is circular; the disk diameter is $0.3 \mathrm{~m}$; the disk thickness is 0.008 $\mathrm{m}$; the distance between adjacent disks of the roller in the axial direction is $0.02 \mathrm{~m}$; centerto-center distance between the rollers is $0.25 \mathrm{~m}$; the roller diameter is $0.057 \mathrm{~m}$; the rotation frequency of rollers with disks is $n=30 \ldots 100 \mathrm{rpm}$; the canting angle of the screen plate working surface is $\alpha=\left(+5^{\circ}\right) \ldots\left(-15^{\circ}\right)$;

- intensifier parameters: the length is $1.5 \mathrm{~m}$; the apron width is $0.175 \mathrm{~m}$; the apron height is $0.23 \mathrm{~m}$; the thickness of the apron sheet is $0.008 \mathrm{~m}$; the step of setting aprons is $0.18 \mathrm{~m}$; the linear speed of apron movement $v=0,2 \ldots 0,5 \mathrm{~m} / \mathrm{s}$;

- conveyor belt parameters: the length is $1.31 \mathrm{~m}$; the width is $0.2 \mathrm{~m}$; the board height is $0.3 \mathrm{~m}$; the linear belt speed is $0.17 \mathrm{~m} / \mathrm{s}$.

First we studied the process of screening gravel particles depending on the change of the canting angle of the screen plate working surface $(\alpha)$ with a constant supply of stones $q=2,9 \mathrm{~kg} / \mathrm{s}$. the Screening was evaluated in terms of screening efficiency $(E)$ and the time of separating process $(\mathrm{t})$. The rotation frequency of rollers with disks was $60 \mathrm{rpm}$, and the speed of moving aprons $-0.32 \mathrm{~m} / \mathrm{s}$. The material for separating was gravel mix consisting of $70 \%$ of low grade grains $(0 \ldots 20)$ and $30 \%$ of high grade grains $(>20)$. Particle size of low grade grains: $(5.10 \mathrm{~mm})$ is $25 \%$; $(10 \ldots 15 \mathrm{~mm})-25 \%$; $(15 \ldots 20 \mathrm{~m})-$ $50 \%$ including "hard grains" - $25 \%$. 
The results of the research are presented in table 1, where one can see an increase in the efficiency and time of the screening process with the change of the plate canting angle from negative values (downward angle) to positive (upward angle) in the direction of stone movement.

Table 1. Efficiency of the screening process.

\begin{tabular}{|l|c|c|c|c|c|}
\hline \multirow{2}{*}{ Parameters } & \multicolumn{5}{|c|}{ Canting angle of plate surface $\alpha$, grade } \\
\cline { 2 - 6 } & $\mathbf{+ 5}^{\mathbf{0}}$ & $\mathbf{0}^{\mathbf{0}}$ & $\mathbf{- 5}^{\mathbf{0}}$ & $\mathbf{- 1 0}^{\mathbf{0}}$ & $\mathbf{- 1 5 ^ { \circ }}$ \\
\hline Screening efficiency $E, \%$ & 99,52 & 99,28 & 99,03 & 97,76 & 96,64 \\
\hline Screening time $t, \mathrm{~s}$ & 14,1 & 13,7 & 13 & 12.6 & 11,8 \\
\hline
\end{tabular}

Analyzing the obtained data, and on the basis of the minimum value of screening efficiency $E \geq 98 \%$ and the minimum time of the process in order to increase the roller plate productivity, the rational range of angles $(\alpha)$ of the screening surface will be $(-2,50) \ldots(-7,50)$. In this case, the angle $(-2.500)$ is the most preferable, since the efficiency of gravel screening was more than $99 \%$.

In order to achieve the best results of the screening process, it was necessary to carry out multifactor planning of the experiment. To do this there were identified the main factors ( $X_{1}$ - the speed of apron moving, $X_{2}$ - the rotation frequency of rollers with disks, $X_{3}-$ the amount of gravel feed), having the greatest impact on the efficiency and time of the screening process. The factors and the range of their variations are presented in table 2.

The material for separating was gravel with the proportion of high grade to the low grade $H / L=50 / 50$. The low grade had the following composition: $5 \ldots 10 \mathrm{~mm}-20.8 \%$; $10 \ldots 15 \mathrm{~mm}-25 \% ; 15 \ldots 20 \mathrm{~mm}-54.2 \%$. In the process of screening the material was separated into two fractions $0 . .20 \mathrm{~mm}$ and $20 \ldots 40 \mathrm{~mm}$.

Table 2. Levels and intervals of varying factors.

\begin{tabular}{|c|c|c|c|c|c|c|c|}
\hline \multirow{2}{*}{ Factors } & \multirow{2}{*}{$\begin{array}{l}\text { Code } \\
\text { value }\end{array}$} & \multirow{2}{*}{$\begin{array}{l}\text { Interval } \\
\text { of } \\
\text { varying }\end{array}$} & \multicolumn{5}{|c|}{$\begin{array}{l}\text { Natural factor levels, } \\
\text { corresponding the coded ones }\end{array}$} \\
\hline & & & $+1,682$ & +1 & $\mathbf{0}$ & -1 & $-1,682$ \\
\hline$v$ - apron speed, $\mathrm{m} / \mathrm{s}$ & $X_{1}$ & 0,05 & 0,40 & 0,37 & 0,32 & 0,27 & 0,24 \\
\hline $\begin{array}{l}n \text { - disk rotation } \\
\text { frequency, rpm }\end{array}$ & $X_{2}$ & 15 & 85,23 & 75 & 60 & 45 & 34,77 \\
\hline$q$ - gravel feeding, $\mathrm{kg} / \mathrm{s}$ & $X_{3}$ & 1,25 & 7,10 & 6,25 & 5 & 3,75 & 2,90 \\
\hline
\end{tabular}

As a result of planning the central composite rotatable plan of the second order, after processing the data of the three-factor experiment regression equations were obtained to determine the efficiency of the screening process (E,\%) and the specific one-hour capacity $(\mathrm{Gu}, \mathrm{m} 3 / \mathrm{m} 2 * \mathrm{~h})$ :

$$
\begin{gathered}
E=98,515+12,822 v-23,36 v^{2}-0,0294 q+0,0023 n-0,0025 n q, \\
G_{u}=17,18 v+3,667 q-0,0096 q n+0,048 n-5,842 .
\end{gathered}
$$


The analysis of the equations (1) and (2) allowed to determine the most rational parameters of the roller screen with round disks, over which movable aprons are installed: the rotation speed of rollers with disks $n=60 \mathrm{rpm}$, the speed of apron movement $v=0,32$ $\mathrm{m} / \mathrm{s}$. With these parameters there were obtained rather high efficiency indexes of screening and specific capacity of the roller screen plate in the whole range of changes in material feed to the rotating disks.

Then, on the basis of the screen with rational parameters comparative studies of gravel fractionating on the separating device with round and multi-faceted (eight-faceted) disks were carried out.

Dependences of the screening efficiency and specific capacity on the gravel feed to the screen plate surface with round and multi-faceted disks are presented in tables 3 and 4, respectively.

Table 3. Roller screen with round disks.

\begin{tabular}{|l|c|c|c|c|c|c|}
\hline$q, \mathrm{~kg} / \mathrm{s}$ & 2,90 & 3,75 & 4,38 & 5 & 6,25 & 7,10 \\
\hline$G_{u}, \mathrm{~m}^{3} / \mathrm{m}^{2 *} \mathrm{~h}$ & 11,51 & 14,13 & 16,23 & 17,99 & 21,85 & 24,48 \\
\hline$E, \%$ & 99,84 & 99,70 & 99,58 & 99,47 & 99,24 & 99,09 \\
\hline
\end{tabular}

Table 4. Roller screen with multi-faceted disks.

\begin{tabular}{|l|c|c|c|c|c|c|}
\hline$q, \mathrm{~kg} / \mathrm{s}$ & 3,12 & 3,75 & 4,38 & 4,80 & 6 & 7 \\
\hline$G_{u}, \mathrm{~m}^{3} / \mathrm{m}^{2} * \mathrm{~h}$ & 11,91 & 12,92 & 13,95 & 14,63 & 16,59 & 18,22 \\
\hline$E, \%$ & 99,63 & 97,69 & 95,75 & 94,46 & 90,76 & 87,68 \\
\hline
\end{tabular}

The data obtained show an obvious advantage of the device with circular disks (table 3 ), where in the whole range of material feed screening efficiency is more than $99 \%$. At the same time, the device with multi-faceted disks (table 4) has a decrease in the screening efficiency from $99.6 \%$ to $87.7 \%$ with an increase in gravel feed from $3 \mathrm{~kg} / \mathrm{s}$ to $7 \mathrm{~kg} / \mathrm{s}$ [7].

The tables also show that the specific capacity on both devices increased with the increase in gravel feed to the screen plate, besides, the screen with round disks has more intensive $G_{u}$ increase. Moreover, under the minimum material feed to the screen both devices had almost equal capacity, then when $q=7 \mathrm{~kg} / \mathrm{s}$ the screen with circular disks (Table 3) $G_{u}$ was $25 \%$ higher compared to multi-faceted disks (Table 4).

Thus, when studying the roller screen test bench with round disks there were defined rational parameters of rotation frequency of the diskcs, the speed of the aprons, the canting angle of the working surface, which provide high efficiency $E \geq 99 \%$ in the whole range of material feed to the screen plate $q=2,9 \ldots 7,1 \mathrm{~kg} / \mathrm{s}$. Comparative evaluation of the roller screen efficiency has proven the advantage of circular discs compared to multi-faceted, when movable aprons are installed over the screening surface.

\section{References}

1. A.V. Kondratyev, Sozdanie visokoeffektivnih valkovih separatorov torfyanih mashin $i$ oborudovaniya, Dis. dokt. tech. nauk [Development of highly efficient roller separators of peat machinery. Extended Abstract of D. Sc. Thesis], 34 p. (Tver, 1998)

2. A.V. Iudin, V.S. Shestakov, Equipment selection the estimation of mobile open pit units schemes when mining karst deposits, Izvestiya Visshikh Uchebnikh Zavedenii. Gornii Zhurnal, 1, pp. 92-100 (2017)

3. FLSmidth. Available at: http://www.flsmidth.com/ 
4. GrandControl. Available at:http://grandcontrol.kz/

5. August-mueller. Available at: http://www.august -mueller.com/cms/index.html

6. A.V. Kondratyev, Influence of roller separation disk form on the efficiency of gravel screening, Mechanization of construction, 1, pp. 36-38 (2014)

7. A.K. Abdulakh, Obosnovanie konstruktsii i parametrov valkovogo grohota dlya sortirovochnikh kompleksov dorozhno-stroitelnikh machin. Dis. kand. tech. nauk [Justification of roller screen construction and parameters for screening units of road building machines. Extended Abstract of C. Sc. Thesis], 19 p. (Tver, 2014). 